vol.4 No.1 - 2017

\title{
INTERNAL MARKETING AND ORGANIZATIONAL CITIZENSHIP BEHAVIOR A COMPARATIVE STUDY IN MANSOURA
} Shaymaa Abd Elmohsen Ali ${ }^{1}$, Wafaa Fathi Sleem ${ }^{2}$ Ahlam Mahmoud EL-shaer ${ }^{3}$

Abstract

Assist Professor of Nursing Adminstration, ${ }^{2,3}$ B. SC Nursing1

Background: Today, intense competition in health environment needs induction and diversion of values added to health service customer such as, internal marketing activities and organizational citizenship behavior enable nurses to provide health services with high quality and increasing hospital productivity and profitability Aim of the study: Find out the relation between the nurses perception of their organization internal marketing activities and organizational citizenship behavior Design: Descriptive, comparative design. Setting: At gastroentroentrology surgical center and Mansoura general hospital. Subjects and methods: The study sample composed of 293 nurse . Data was collected by using (Multifactor of internal marketing questionnaire and Organizational citizenship behavior questionnaire) Results: revealed that there was statistically significant relationship between internal marketing and organizational citizenship behavior $(\mathrm{P}<0.05)$. conclusion: most of nurses have low perception toward internal marketing activities ,and majority of them have (high- moderate ) level of agreement concerning organizational citizenship behavior. Recommendation: Mangers should develop a plane for internal marketing application in their hospitals to enhance their health service quality also, selecting, retain, evaluating nurses for organizational citizenship behavior. In addition, Provide good work environment to nurses ( providing possible supplies that make their work easy and interesting) and collaborative atmosphere ( encourage colleagues to help other especially with heavy work). Key words: Internal Marketing, Organizational Citizenship Behavior.

\section{Introduction:}

Today's challenges facing the health sector make competition, increase due to many forces such as globalization, technology and high growth in patient expectation 1. Internal marketing, introduces innovative ways for training and retraining of their nurses and creating a positive attitude in improving quality of patient health service ${ }^{2}$.

These nurses not only perform their works well, but also work, skipping their organizational official responsibility, thus organizational citizenship behavior contribute to service quality, patient satisfaction and organizational efficiency ${ }^{3,4}$.

Internal marketing is a philosophy for managing the organization's human resources based on a marketing view to motivate nurses at all levels of the organization for always improvement in the way they serve external customers (patient) and each other. Effective internal marketing responds to nurse needs, as it advances the organization's mission and goals $^{5}$, moreover, it can be a useful tool to overcome internal resistance during a major change process in the health organization $^{5}$.

Internal marketing is a mechanism for instilling a "customer orientation" within a healthy organization as a prerequisite for instilling and strengthening the service orientation, customer orientation, and marketing orientation among health organization personnel ${ }^{6}$.

High performance of internal marketing practices will communicate 
nurses about the humanistic values. It will convey that the health organization cares about their happiness and is ready to trust them. Therefore will be able to achieve competitive advantage through discretionary behaviors those are not included in the job description, but lead to health organizational effectiveness if it's performed by the nurses ${ }^{7}$.

Organizational citizenship behavior is a group of willing behavior that are not part of the nurses official tasks ${ }^{8}$. Also, it is a willingness of a nurse to work, skipping their job scope which will indirectly increase the organization performance ${ }^{9}$.

Organizational citizenship behavior can be defined as an advocate when the organization is criticized or behaviors that pass the habit expectation, or arouse colleges to invest in the organization ${ }^{\mathbf{1 0}}$.

So that, there is a need to assess the relation between internal marketing and organizational citizenship behavior which it can improve quality of health services in Health care organization that require highly skilled nurses to implement internal marketing strategies'.

The aim of the current study is to assess the relation between nurses perception of their organization's internal marketing activities and organizational citizenship behavior.

\section{Research questions}

- RQ1: What is the nurses perception of internal marketing activities at the Mansoura General Hospital and Gastroenterology Surgical Center?

- RQ2: What is the nurses organizational citizenship behavior at the Mansoura General Hospital and Gastroenterology Surgical Center?

- RQ3: Is there a relation between the nurses perception of internal marketing activities and organizational citizenship behavior at Mansoura General Hospital and Gastroenterology Surgical Center?

\section{Methodology: \\ Subject and methods : . \\ Research design \\ Descriptive, Comparative study.} Subjects:

The subjects of this study included nurses work in the Gastroenterology surgical center and Mansoura General hospital. The total number of shared nurses was 395 nurses, 119 nurse work at Gastroentrology surgical center and 174 nurse work at the Mansoura general hospital.

\section{Study setting:}

1- Gastroenterology Surgical Center : affiliated to Mansoura university hospitals with a bed capacity (115) beds, it include outpatient, (2) intensive care unit ,operation department ,(5) inpatient department .

\section{2-Mansoura General Hospital :} affiliated to ministry of health with a bed capacity (115) beds, it include outpatient, operation department ,toxicology department, sterilization department, 9 inpatient department namely ( surgical, medical, obstetric, pediatric, orthopedic , nursery, kidney, heart and emergency department).

There are two tools for data collection:

Tool I: Multifactor of internal marketing questionnaire:

The questionnaire consists of two parts.

Part one: related to personal characteristics includes as age, educational qualification, hospital name, marital status and years of experience.

Part two: developed by (Jou, et al. , 2008)to measure nurses perceptions of their organization's internal marketing activities, include (26 items) under four dimensions, communication (9 items), leadership (6 items), benchmarking and job quality (6 items), promotional activities (5 items).A group of 26 items were evaluated through a 5 point to Likert type response scale ( $1=$ strongly disagree 
INTERNAL MARKETING AND ORGANIZATIONAL etc ...

5=strongly agree). Scores was calculated and classified into three levels, High $(>75 \%)$, Moderate $(50 \%-75 \%)$, Low $(<50 \%)$ according to the cutoff point $(50 \%)$.

Tool II: Organizational citizenship behavior questionnaire:

This tool was developed by (Fox and paul,2011) used to assess the nurses organizational citizenship behavior .The questionnaire include 39 items, it divided into 5 dimension, training and development (6 items), work-life policies (4 items), empowerment practices (9 items), organizational commitment (8 items), interpersonal harmony (12 items). A set of 39 items was evaluated via a 3 point to likert type response scale (1=disagree $2=$ uncertainly $3=$ agree). Scores were calculated and classified into three levels, High (>75\%), Moderate $(50 \%-75 \%)$, Low $(<50 \%)$.According to cutoff point $(50 \%)$

\section{Methods:}

All tools, Multifactor internal marketing questionnaire and organizational citizenship behavior questionnaire translated and offered to five experts from nursing administration department, faculty of nursing, Mansoura University.

Pilot study:

It done on $10 \%$ (36 nurse) of studied nurses, to ensure the clarity of the tools language., identify obstacles and to determine the time consumed for filling the sheet. Reliability test of the study tools were tested by alpha Cronbagh. Reliability was computed and found (0.925) for internal marketing and (0.876) for organizational citizenship behavior items.

\section{Field work:}

The data were collected from nurses working in General hospital and gastroenterology surgical center from the beginning of December 2015 and to the end of January 2016.

Formal approval was obtained through official letters from the dean of Mansoura faculty of nursing that was sent to the directors of the Mansoura general hospital and gastroenterology surgical center explaining the aim of the study.

\section{Ethical consideration:}

Prior to the pilot study, ethical approval was obtained from the research ethics committee of the faculty of nursing Mansoura University, The researcher clarified the objective and aim of the study to the nurses included in the study. They were assured confidentiality would be ensured, they have the right to withdraw from the study at any time they decide.

\section{Statistical Analysis}

Statistical analysis was done by using SPSS software (Statistical Package for the Social Sciences version 22, SPSS Inc. Chicago, IL, USA).For quantitative data, the range, mean and standard deviation were calculated. For qualitative data, Chisquare test $\left(\chi^{2}\right)$ paired t-test, $Z$ value of Mann-Whitney test was used. The correlation between variables was evaluated using Pearson's correlation coefficient (r). Significance was adopted at $\mathrm{p}<0.05$. 
Shaymaa Abd Elmohsen Ali et.al.

Results:

Table(1):personal characteristics of the studied nurses (in Mansoura hospitals) (n=293)

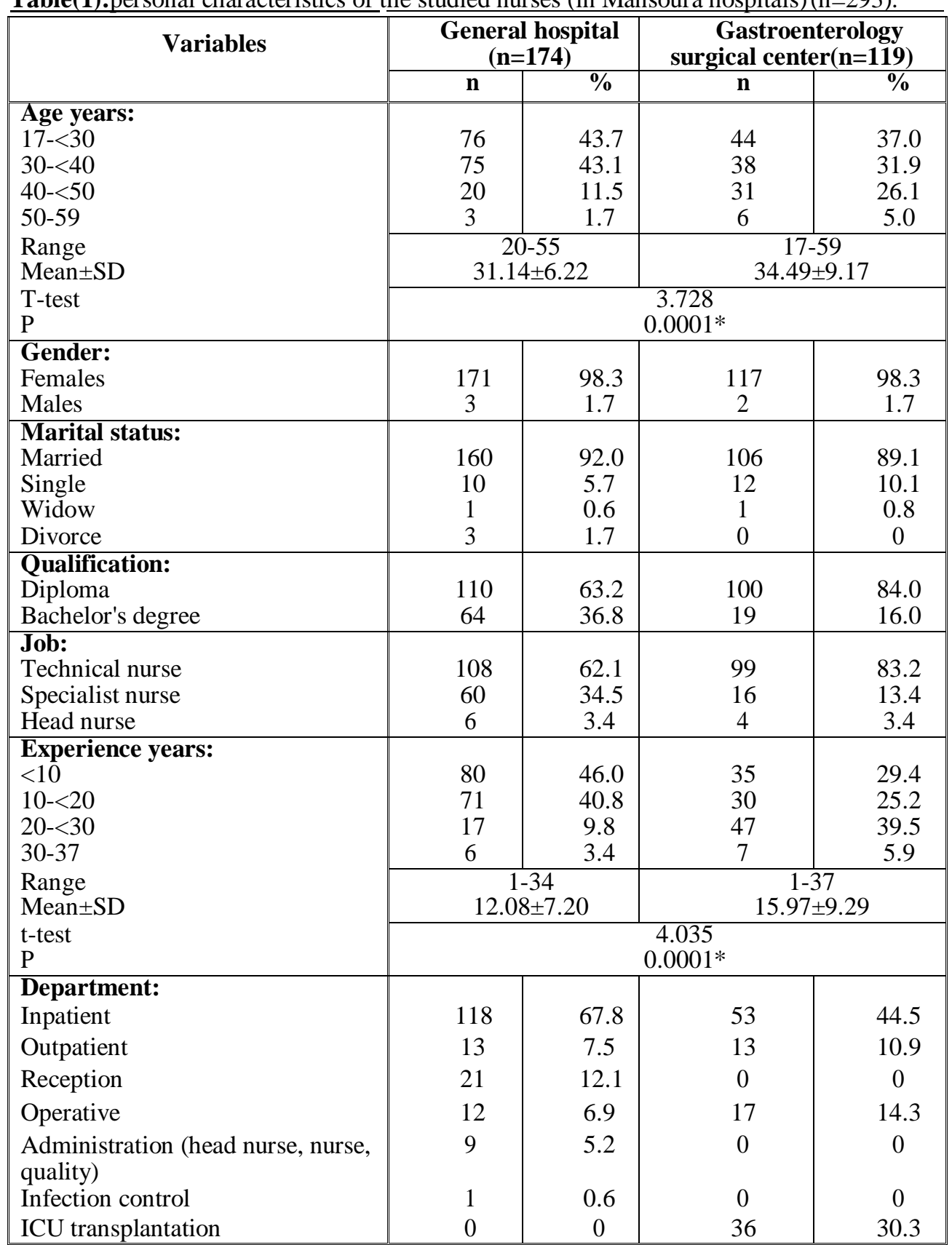

*Significant $(\mathbf{P}<0.05)$.

\section{6}


Table(1): Shows personal characteristics of the studied nurses (in Mansoura general hospital and gastroenterology surgical center) $(n=348)$. The table shows the majority of nurses in general hospital in the age group $(17-<30)$ with a mean score $(31.14 \pm 6.22)$. $(43.7 \%)$ most of them were females, married, having diploma degree and working as technical nurse. while Gastroenterology surgical center nurses were in the age group (17<30) with a mean score $(34.49 \pm 9.17)$. $(37 \%)$ most of them were females, married, having diploma degree and working as technical nurse.

Table (2): Mean total scores and Levels of the studied nurses' perception (in Mansoura hospitals) about their organization internal marketing $(n=293)$.

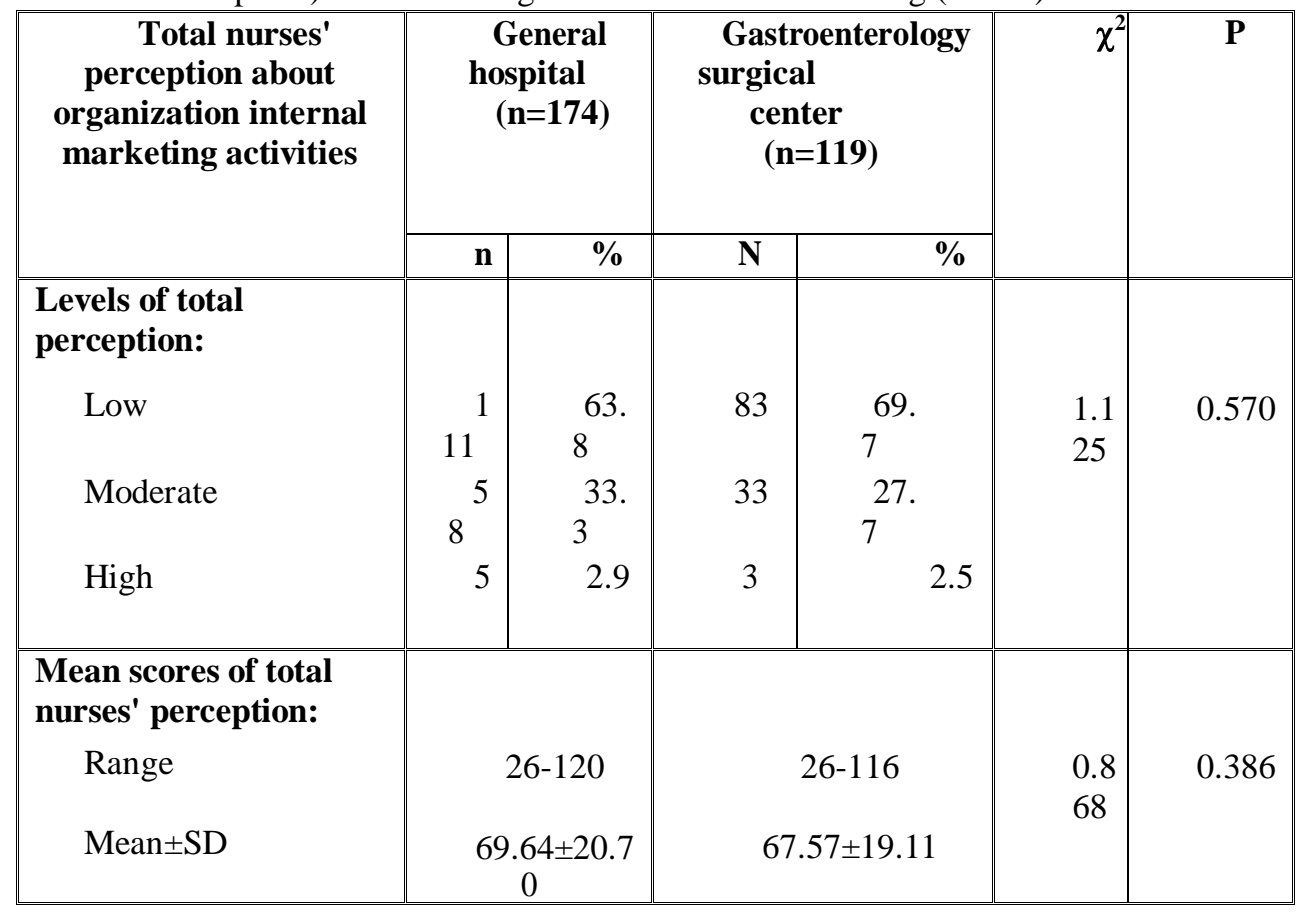

Table (2): Shows total mean scores and levels of the studied nurses' perception (in Mansoura hospitals) about their organization internal marketing $(n=293)$. The table demonstrates nurses perception level in general hospital, low level is $(63.8 \%)$, and gastroenterology surgical center nurses perception, low level is $(69.7 \%)$. The table also pointed to the total mean score of two hospitals, general hospital is (69.64), the gastroenterology surgical center is $(67,57)$. 
Shaymaa Abd Elmohsen Ali et.al.

Table (3): Total mean scores and Levels of the studied nurses' organizational citizenship behaviors (in Mansoura hospitals) $(n=293)$.

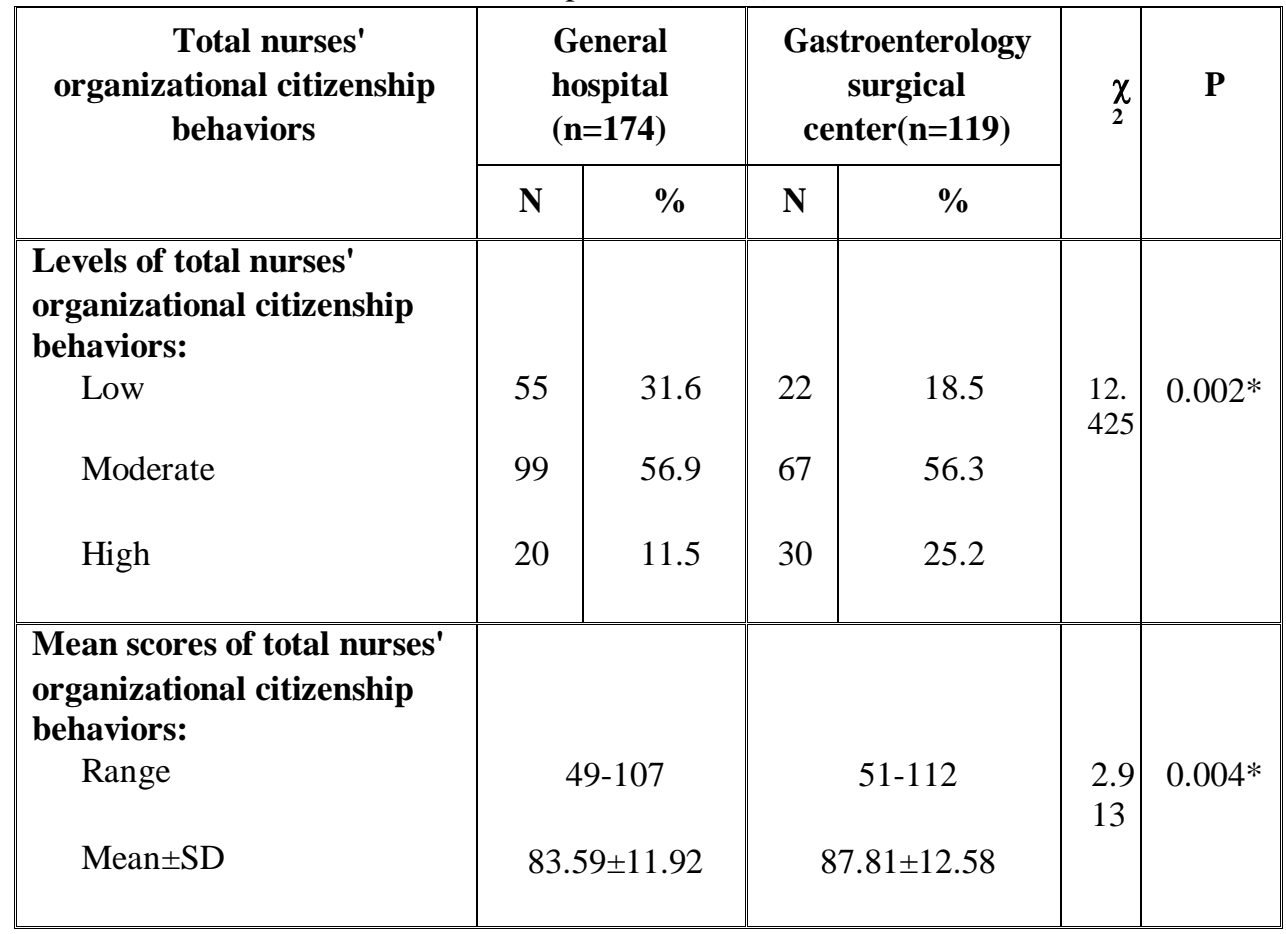

*Significant $(\mathbf{P}<0.05)$

Table (3): Shows Total mean scores and Levels of the studied nurses' organizational citizenship behaviors (in Mansoura hospitals). The table explains nurses level of organizational citizenship behavior in general hospital, high level and moderate level is $(11.5 \%),(56.9 \%)$, but in the gastroenterology surgical center, high level and moderate level are $(25.2 \%),(56.3 \%)$. Furthermore, there is a statistical difference between total mean score in two hospitals, general hospital is (83.59), the gastroenterology surgical center is (87.81). 
INTERNAL MARKETING AND ORGANIZATIONAL etc ...

Table (4): Correlation between sub items scores of the studied nurses' perception about their organization internal marketing activities and their organizational citizenship behaviors (in Mansoura hospitals) $(n=293)$.

\begin{tabular}{|c|c|c|c|c|c|c|c|c|}
\hline \multirow{3}{*}{$\begin{array}{l}\text { Scores of the studied } \\
\text { nurses' organizational } \\
\text { citizenship behaviors } \\
\text { sub items in } \\
\text { Mansoura }\end{array}$} & \multicolumn{8}{|c|}{$\begin{array}{l}\text { Scores of the studied nurses' perception sub items about their } \\
\text { organization internal marketing activities in Mansoura } \\
\qquad(\mathrm{n}=293)\end{array}$} \\
\hline & \multicolumn{2}{|c|}{ Communication } & \multicolumn{2}{|c|}{ Leadership } & \multicolumn{2}{|c|}{$\begin{array}{l}\text { Benchmarking } \\
\text { and job quality }\end{array}$} & \multicolumn{2}{|c|}{$\begin{array}{c}\text { Promotional } \\
\text { activities }\end{array}$} \\
\hline & $\mathbf{r}$ & $\mathbf{P}$ & $\mathbf{r}$ & $\mathbf{P}$ & $\mathbf{r}$ & $\mathbf{P}$ & $\mathbf{R}$ & $\mathbf{P}$ \\
\hline $\begin{array}{l}\text { Training and } \\
\text { development }\end{array}$ & 0.591 & $0.0001^{*}$ & 0.521 & $0.0001 *$ & 0.396 & $0.0001^{*}$ & 0.421 & $0.0001^{*}$ \\
\hline Work- life policies & 0.080 & 0.172 & 0.095 & 0.101 & -0.122 & $0.037 *$ & 0.101 & 0.083 \\
\hline $\begin{array}{l}\text { Empowerment } \\
\text { practices }\end{array}$ & 0.474 & $0.0001 *$ & 0.497 & $0.0001 *$ & 0.304 & $0.0001^{*}$ & 0.248 & $0.0001^{*}$ \\
\hline $\begin{array}{l}\text { Organizational } \\
\text { commitment }\end{array}$ & 0.424 & $0.0001^{*}$ & 0.379 & $0.0001 *$ & 0.293 & $0.0001^{*}$ & 0.218 & $0.0001^{*}$ \\
\hline Interpersonal harmony & 0.260 & $0.0001^{*}$ & 0.326 & $0.0001 *$ & 0.082 & 0.161 & 0.079 & 0.177 \\
\hline
\end{tabular}

*Significant $(\mathbf{P}<\mathbf{0 . 0 5})$

$r=$ Correlation Coefficient

Table (4): Shows correlation between sub items scores of nurses' total perception about their organization's internal marketing activities and their organizational citizenship behaviors (in Mansoura hospitals). The table reveals significant positive correlation between organizational citizenship behavior items and internal marketing items except work-life policies with communication, leadership and promotional activity. In addition to organizational citizenship behavior with benchmarking \& job quality and promotional activities.

Table (5): Correlation between total perception of internal marketing activities and organizational citizenship behaviors among the studied nurses' (in Mansoura general hospital and gastroenterology surgical center) $(\mathrm{n}=293)$.

\begin{tabular}{|c|c|c|c|c|c|c|}
\hline \multirow[t]{3}{*}{ Variable } & \multicolumn{6}{|c|}{$\begin{array}{l}\text { Total scores of internal marketing activities in } \\
\qquad(\mathrm{n}=293)\end{array}$} \\
\hline & \multicolumn{2}{|c|}{$\begin{array}{c}\text { General } \\
\text { hospital } \\
(n=174)\end{array}$} & \multicolumn{2}{|c|}{$\begin{array}{l}\text { Gastroenterology } \\
\quad \begin{array}{l}\text { surgical } \\
\text { center }(n=119)\end{array}\end{array}$} & \multicolumn{2}{|c|}{$\begin{array}{r}\text { Total } \\
(n=293\end{array}$} \\
\hline & $\overline{\mathbf{R}}$ & $\mathbf{P}$ & $\overline{\mathbf{R}}$ & $\mathbf{P}$ & $\mathbf{r}$ & $\mathbf{P}$ \\
\hline 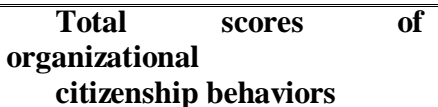 & $\begin{array}{l}0 . \\
646\end{array}$ & $\begin{array}{l}0.00 \\
01 *\end{array}$ & $\begin{array}{c}0 . \\
460\end{array}$ & $\begin{array}{l}0.000 \\
1 *\end{array}$ & $\begin{array}{r}0 . \\
553\end{array}$ & $\begin{array}{c}0.0 \\
001^{*}\end{array}$ \\
\hline
\end{tabular}

*Significant $(\mathbf{P}<0.05)$

$\mathbf{r}=$ Correlation Coefficient 


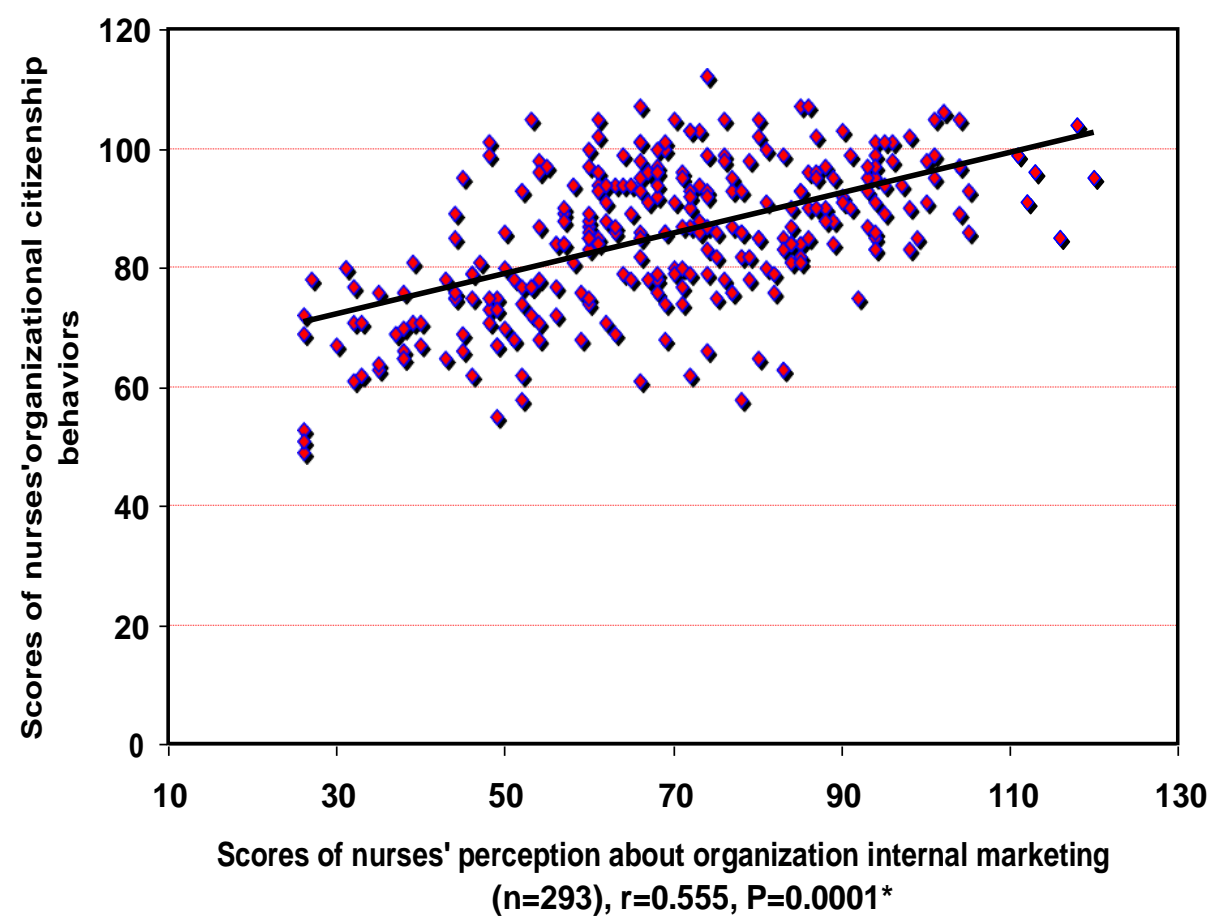

Figure (1): Correlation between total perception of internal marketing activities and organizational citizenship behaviors among the studied nurses' at (in Mansoura hospitals) $(n=293)$.

Table (5) figure (1): Shows correlation between total perception of internal marketing activities and organizational citizenship behaviors among the studied nurses' (in Mansoura hospitals). The table reveals highly significant correlation between internal marketing and organizational citizenship behavior among nurses working in general hospital and gastroenterology surgical center.

\section{Discussion:}

Today, health organization face competition for quality of health services.(Chio, et al., 2004 \& Frieses, 2012) Internal marketing and organizational citizenship behavior produce a flexible and innovative work force in extensive dynamic changes and sever competition $^{\mathbf{1 1 , 1 2}}$.

The present study show that the most of nurses had low perception toward internal marketing activities both, in general hospital and in gastroenterology surgical center. This results may be due to nurses not satisfied with item of (promotional activities, work environment , salaries and fringe benefits ), manger's not give attention to internal marketing as a strategy or a tool for enhancing their organization performance, lack awareness of mangers about importance of internal marketing and how to apply, no special plan for integrating internal marketing in organizational activities. On contrary, Ching \& Chang (2009)disagreed with the present study, nurses had favorable perception of internal marketing, $\mathrm{He}$ explained that hospital provided good communication channels, provided good enterprise culture, and nurses treated as 
INTERNAL MARKETING AND ORGANIZATIONAL etc ...

internal customers, made them satisfied to achieve its objectives ${ }^{\mathbf{1 3}}$. In addition, Tasi, (2014) also disagreed with the present results, He found high perception of nurses toward internal marketing activities ${ }^{14}$.

The present study show that the majority of nurses have (high-moderate) level of agreement toward of organizational citizenship behavior and it's items in general hospital and more than two third in gastroenterology surgical .This high level of agreement may be due to, nurses satisfied with most items of organizational citizenship behavior (training and development, empowerment, organizational commitment, interpersonal harmony behavior). In congruence with the following study finding, Dargahi, et al., (2012)found that most nurses in the study had (O.C.B) ${ }^{15}$. In addition, Jafari, et al., (2015)agreed with the present who reported that, the organizational citizenship behavior was above the accepted level $^{16}$. In same lien, Mahmoud \& Ibrahim, (2016)agreed with the present results two-third of nurses demonstrate organizational citizenship behavior ${ }^{17}$.

While the present finding disagreed with Sharma,et al.,(2011) finding, who reported that, public sector organization had greater degree of organizational citizenship behavior in comparison to private sector organizations ${ }^{\mathbf{1 8}}$.He explained that competitiveness was very high in private sector organization, which hinders nurses of the private sectors to exhibit high level organizational citizenship behavior. From researcher point of view, organizational citizenship behavior level not affected by circumstances that face nurses, it's Extrarole behavior practices by nurses will and is backed to their culture. Results of, Baykal, \& Altuntas (2014)gone away from the present finding, nurses employed in the ministry of health hospitals demonstrated low level of organizational citizenship behavior ${ }^{19}$.

The present study revealed that there was a significant positive correlation between nurses perception of internal marketing and organizational citizenship behavior in Mansoura setting. This results may be due to internal marketing provide tools and strategies (training, communication, promotion and good work environment) that concern with nurses needs and expectation, when fulfilling this needs and expectation .nurses are ready to exerts more efforts in order to help their organization to achieve its objective .The present study consistent with, agreed Bambale, (2011) on the same results, He found significant relationships between organizational citizenship behavior and marketing (communication, leadership, service climate) and work autonomy increased organizational citizenship behavior ${ }^{20}$.As well as, Dvila, (2013)agreed with the same opinion, his results reveals that internal marketing element increase Ext-role behavior $^{21}$.Kamalinasab, et al., (2014), also with the same opinion ${ }^{22}$.His view that internal marketing viewed nurses as internal customer \& view job as a product. This approach would formed and improved extra-role behaviors along with organizational citizenship behavior that would improve service quality. As well as,(Awan, et al., 2015)reported a positive relationship between internal marketing, organizational citizenship behavior and organizational commitment ${ }^{23}$. His results demonstrated that internal marketing contribute to employee satisfaction with pay, promotion and benefits lead to commitment and extra-role behavior. Furthermore, Salajegh, et al., (2015) found apositive relation between organizational citizenship behavior items and internal marketing ${ }^{24}$. 


\section{Conclusion:}

Most of the nurses have low perception toward internal marketing activities, and majority of them have (high- moderate) level of agreement toward organizational citizenship behavior and there is a statistical significant positive correlation between organizational citizenship behavior and internal marketing in both hospitals.

\section{Recommendation:}

Based on the results of this study, it was recommended that, Developing a plan for internal marketing application to enhance health service quality, and enhance nurses behavior of organizational citizenship behavior. Disseminate the awareness of internal marketing, among nurses in their Hospitals by designing educational session and programs.

Provide a good work environment for nurses (providing possible supplies that make their work easy and interesting) and collaborative atmosphere (encourage colleagues to help others especially with heavy work).

\section{References}

1-Susanti,Ch.,(2015): The Influence of Internal Service Quality toward Patient's Behavioral Intention in Inpatient Unit at the Type C General Hospitals in East Java, Indonesia, Journal of Nursing and Health Care, 3 (1) 171-178.

2- Ebrahimpour, H., Zahed, A., Khaleghkhah, A., \&Sepehri, M., (2011) : A survey relation between organizational culture and organizational citizenship behavior, Journal Procedia - Social and Behavioral Sciences,30 1920-1925.

3-Bansal, H., Mendelsonb,M., \&Sharmac,B., (2015): The impact of internal marketing activities on external marketing outcomes, Journal of Quality Management 6 (2001) 6176
4-Luigi,D., Oana,S., Mihai,T., \&Simona, A., (2015): achieving employee satisfaction by pursuing sustainable practices, Studies in business and economics, 6 (1) 37- 45.

5-Anosiky, P. \& Ahmed, p. (2006): Internal Marketing from perception to practice, working paper series,Aviliableathttps://www.wlv.ac.u k/.../uwbs-wp005-06-anosikeahmRetrived on 7th June 2014archieves14.webs.com/18-28.pdf, Retrieved on 2and may 2015.

6- Vazifehdoost,H., \&Hooshmand,S. (2012): The Effects of Internal Marketing and Organizational Commitment on Bank's Success, International Journal of Business and Commerce, 1(9) 1-15.

7-Dash, S., \&Pradhan, R., (2014):Determinants \& Consequences of Organizational Citizenship Behavior: A Theoretical Framework for Indian Manufacturing Organizations, International Journal of Business and Management Invention , 3(1) 17-27.

8-Reza,M., Mahmoudi, M., \&Ekhtari,H.,(2014): Providing A Conceptual Model For Surveying The Impact of Empolyee Empowerment on Organizational Citizenship Behavior (OCB)in Alborz Insurance Company, Journal of current research and science 2(6) 794-800.

9-Khan,S., (2015): The Factors affecting Organizational Citizenship Behavior: A Study in the Fitness Industry, International Journal of Recent Advances in Organizational Behavior and Decision Sciences (IJRAOB), An Online International Research Journal 1(2) $373-383$.

10- Bukhari, Z., (2008): Key Antecedent of Organizational citizenship Behaviors in Banking sector of Pakistan. International journal of business management, 3 (12) 106-115. 
INTERNAL MARKETING AND ORGANIZATIONAL etc ...

11- Chio, J., Larson, E., Bakken, S., Stone, P., (2004): Perceived nursing work environment of nurses, nursing research journal, 53 (6): 370-378.

12-Frieses, Ch., (2012): practice Environments of nurses Employed in Ambulatory Oncology Settings :measure Refinement, Available at, https:// www. Ncbi. nlm. NIH. Gov/ poems/articles/ PMC3296284/, retrieved on $4^{\text {th }}$ October2016.

13-Ching, H.,\&Chang, Ch., (2009): perception of Internal Marketing and Organizational Commitment by Nurses, Journal of Advanced Nursing, 65 (1) 92-100.

14- Tasi, Y., (2014): Learning organizations, Internal Marketing, and Organizational commitment in hospital. Available at https://www.ncbi.nlm.nih.gov/pubmed/ 24708601, retrieved on $1^{\text {st }}$ November 2016.

15- Dargahi, H., Alirezaie, S., \&Sham,G., (2012): Organizational Citizenship Behavior among Iran Nurses, Iranian Journal Public Health, 41(5) 85-90.

16- Jafari, S., Afshin, T., Jafari, K., Barzegar, M., (2015): Evaluation of organizational commitment among nurses in intensive care units, Journal of Nursing and Midwifery Sciences 2 (3) 38-43.

17- Mahmoud, A., \& Ibrahim, S., (2016): Factors in Nurses' Organizational Citizenship Behavior, Journal of Nursing and Health Science, 5(2)2228.

18- Sharma, J., Bajpai, N., \&Holani, U., (2011): Organizational Citizenship Behavior in Public and Private Sector and Its Impact on Job Satisfaction: A Comparative Study in Indian Perspective, International Journal of Business and Management, 6(1) 67-75.
19- Baykal, U., \&Altuntas, S., (2014): Organizational Citizenship Behavior Level of Nurses and Effective Factors, Journal of Health and Nursing Mangment, 1(2) 89-98.

20- Bambale, A., (2011): Marketing and Organizational Citizenship Behavior : A Review of Literature, available athttp://wwww. businessjournalz. org/cmr, Retrived on $4^{\text {th }}$ April 2015.

21- Dvila, M., (2013): A Study of the Effects of Internal Marketing on Customer-oriented Prosocial Behaviors, International Journal of Academic Research in Business and Social Science, 3 (11) 253-269.

22- Kamalinasab, H., \& Sami, A., \&Zendehdel, A., (2014): Internal Marketing, Organizational Citizenship Behavior and Quality of Service, Applied Mathematics in Engineering, Management and Technology, 2(4) 492-495.

23- Awan, H., Siddiquei1, A., Jabbar, A., Abrar, M., \& Ahmad ,S., (2015): Internal Marketing and Customer Loyalty: A Dyadic Analysis, Journal of Service Science and Management, Available at http://www.scirp.org/journal/jssm, Retrieved on 7th June 2015.

24-Salajegh, S., \&Farabhbakhsh, A., \&Sohi, Z., (2015): Explaining the Relationship between Internal Marketing Activities with Organizational Citizenship Behavior among Employees of Tejarat Bank, Indian Journal of Fundamental and Applied science 5 (1) 3644-3655. 